\title{
Anthropogenic and Climatic Causality of Changes in the Hydrological Regime of the Dnieper River
}

\author{
Vitalii Ivanovich Pichura ${ }^{1 *}$, Larisa Aleksandrovna Potravka1, \\ Petro Mikhalovich Skrypchuk ${ }^{2}$, Natalia Vladimirovna Stratichuk ${ }^{1}$ \\ 1 Kherson State Agrarian University, Ukraine, 73006, Kherson, Stritens'ka str. 23 \\ 2 National University of Water and Environmental Engineering, Ukraine, 33028, Rivne, Soborna str. 11 \\ * Corresponding author's e-mail: pichuravitalii@gmail.com
}

\begin{abstract}
The intensive use of water resources and the transformation of natural landscapes under the influence of human economic activity have led to changes in the natural water balance of river drainage basins. The negative processes thereof are intensified by climatic changes that have significantly disturbed the hydrological regime, determined by changes in water content and river flow dynamics. The retrospective study and prediction of the flow of the Dnieper River was carried out using multivariate statistics and adaptive methods of nonlinear time series analysis. The anomalous features were identified and the main periods of changes in the water regime of the river for 190 years (1818-2008) were determined using the standard root-mean-square deviation and wavelet analysis. As a result of non-linear prediction, it was determined that if the tendency of anthropogenic and climatic formation of the water regime of the Dnieper River sustains, there is a $90 \%$ probability of insignificant but steady trend and cyclical reduction of the average annual flow by $1.6 \mathrm{~m}^{3} / \mathrm{s}$ per year to $1120 \pm 270 \mathrm{~m}^{3} / \mathrm{s}$ by 2040 . The results of the detailed retrospective analysis for 190 years and the prediction of the probability of changes in the flow of the Dnieper river confirm the previous conclusions of many scientists regarding the significant transformation of the ecosystem of the transboundary river and provide new knowledge regarding the main stages of formation of the water regime and the probability of further regulation of the flow of the Dnieper river if the current conditions of the negative impact of economic activities are maintained in the transboundary basin.
\end{abstract}

Keywords: water regime, river flow, Dnieper River, retrospective analysis, multivariate statistics, Wavelet analysis, Holt-Winters method, prediction.

\section{INTRODUCTION}

The study of patterns of formation and changes in hydrological regime and flow of rivers is one of the main tasks of the land hydrology. The nature of long-time changes in the water regime of rivers, especially in unstable climate and under increasing influence of anthropogenic factors, has not been sufficiently studied. Intensive use of water resources and transformation of natural landscapes under the influence of human economic activity has led to changes in the natural water balance of river drainage basins. It significantly disturbed the hydrological regime that is determined by changes in water content and dynamics of river flow. The water regime of many rivers is disturbed by economic activities in watercourses (dams for timber rafting, small hydroelectric stations, artificial regulation and redistribution of flow, etc.) and in drainage basins (plowing of land, deforestation, hydromelioration, etc.) (Prytkov et al., 2007; Cesoniene et al., 2017; Kacienè, 2018; Dudiak et al., 2019). For many years, the process of formation of river flow that is determined by patterns of long-term fluctuations and seasonal variations was considered as the result of many factors, which determines mainly scholastic approach to study of these patterns (Kartvelishvili, 1981; Ratkovich, 1997). However, the results of other studies (Jayawardena et 
al., 2002; Sivakumar, 2004; Regonda et al., 2004; Kovalenko et al., 2008; Kuzmenko et al., 2012; Lisetskii et al., 2015) indicate the availability of deterministic chaos in multi-year series of river flow, which can be determined using complementary linear, nonlinear and spectral methods of multivariate statistics and time series analysis. The use of these methods enables to get a detailed picture of flow formation mechanisms and can be used in practice in solving of problems of retrospective analysis, interpolation and extrapolation of hydrological time series and their prediction.

Retrospective analysis of flow dynamics is the necessary element of modelling and detailed study of changes in the state of natural and natural-technical systems that are connected with the use of water resources. Changes in water content affect the technical and economic conditions of functioning of economic entities and complexes, determine potential costs for protection against dangerous hydrological processes, level of life comfort and, finally, health and well-being of population. The analysis and prediction of flow is considered in many publications as an interdisciplinary task. Its satisfactory solution involves consideration of many factors, complexity and inconsistency of their interaction. Identification of variations in the hydrological regime with time allows to study in detail the flow formation periods and to determine the beginning of its transformation. This provides an opportunity to understand the influence of retrospective causes on formation of current trends in the dynamics of hydrological characteristics.

As a result of a large-scale river development (in the period from 1934 to 1976), the water regime of large valley-river areas of the Dnieper River was artificially transformed from river regime to the lake one. It has led to a rapid slowdown in the water masses circulation and occurrence of large stagnation zones. Creation of reservoirs of the Dnieper cascade enabled to significantly increase water resource potential of Ukraine. However, at the same time it caused distortion of water flow, water eutrophication, significant flooding of coastal areas, abrasion of banks, rise in groundwater level, increase of groundwater flow volume, increase of groundwater pollution level, violation of feeding of a river from soil and other processes. The accumulation of silt caused a violation of water exchange between surface water and groundwater. Evaporation from the surface of reservoirs reaches up to $4.5 \mathrm{~km}^{3} /$ year.
The anthropogenic transformation of the hydrological regime and the significant reduction in the flow are the causes of degradation of the aquatic ecosystem of the Dnieper River. Identification of a tendency to change a river flow is a difficult task due to the imperfection of measurement methods, spatial variation of parameters, stochastic nature of change and other reasons.

In this regard, the analysis of actual data (Osadchii et al., 2008) by different scientists shows inconsistent and contradictory results: in one case, they consider that the flow increases (Khilchevskyi et al., 2007; Vyshnevskyi et al., 2011); in other case, they reveal no tendencies (Hrebin, 2007) and consider the dynamics to be chaotic (Yushkina, 2007); in the third case, the researchers justify the availability of a negative trend (Andrianova et al., 2003; Lisetskiy et al., 2013). The inconsistency of the results largely depends on irregularity of the observation periods and the diversity of the applied methods of statistical data processing. Many scientists believe that changes in the flow are caused by solar activity cycles and climate change. More obvious cause of formation of the flow dynamics is the construction of a cascade of reservoirs, which has led to distortion of natural recharge of the Dnieper River.

The purpose of the research work is the retrospective analysis, identification of the main periods of flow transformation of the Dnieper River in a period from 1818 till 2008 and the prediction of probability of a change thereof by 2040 using multivariate statistics and adaptive nonlinear prediction methods.

\section{MATERIALS AND METHODS}

The Dnieper river is one of the largest rivers of Europe, the swimming pool which is 511 thousand $\mathrm{km} 2$ and is located within three states (Fig.1) - the Russia (19.8\% of the total area of the pool), Belarus $(22.9 \%)$, and Ukraine $(57.3 \%)$. Crossborder Dnieper basin is a diversified complex that has a high natural and socio-economic value to the three neighboring countries. Because of historical patterns of development of the Ukrainian part of the Dnieper river basin in its territory is more than $60 \%$ of total industrial production in Ukraine. The area of arable land trans-boundary basin is 283 thousand $\mathrm{km} 2$, or $55.4 \%$ of the total area of the basin, of which 206 thousand $\mathrm{km}^{2}(72.8 \%)$ are 
in Ukraine. About half the state's population resides in the territory of the basin and two thirds drink water from the Dnieper. Therefore, taking into account the conditions of high anthropogenic load for the rational management of natural resources the search for optimal interaction between management, man and nature is necessary, i.e. the formation of balanced relations between the exploitation geo-hydro-ecosystem their guard and purposeful transformation (The Ecological Condition ..., 2009; Lisetskii at al., 2015).

The changes in the flow of the Dnieper River (Q m $3 / \mathrm{s}$ ) were studied over a 190-year period - since 1818 till 2008: 1818-1975 (gidropost - I) - the original sources of data of $\mathrm{H}$. I. Shvets (1979), 1976-2008 (gidropost - II)- actual observations of the Kherson Hydrobiological Station of the National Academy of Agrarian Sciences of Ukraine (Korzhov, 2007).
The retrospective analysis of the flow change was carried out using multivariate statistics and time series analysis methods. In order to identify the type of the function of the density distribution curve for annual flow, the following variations thereof were used: normal, beta, exponential, extreme, gamma, geometric, laplace, logistic, lognormal, poisson, rayleigh, weibull. This has enabled to determine that the changes of the flow dynamics in time fall under the law of unimodal lognormal distribution. This indicates the obedience of the input data to the normal distribution under $\mathrm{Ln}(\mathrm{Q})$, which provided the possibility to bring a non-stationary process to a stationary one for further detailed study of the components of dynamic processes of water regime formation:

$$
Q_{\mathrm{t}}=T_{t}+S_{t}+C_{t}+\varepsilon_{t}
$$

where: $Q_{t}$ is the input data of the flow dynamics;

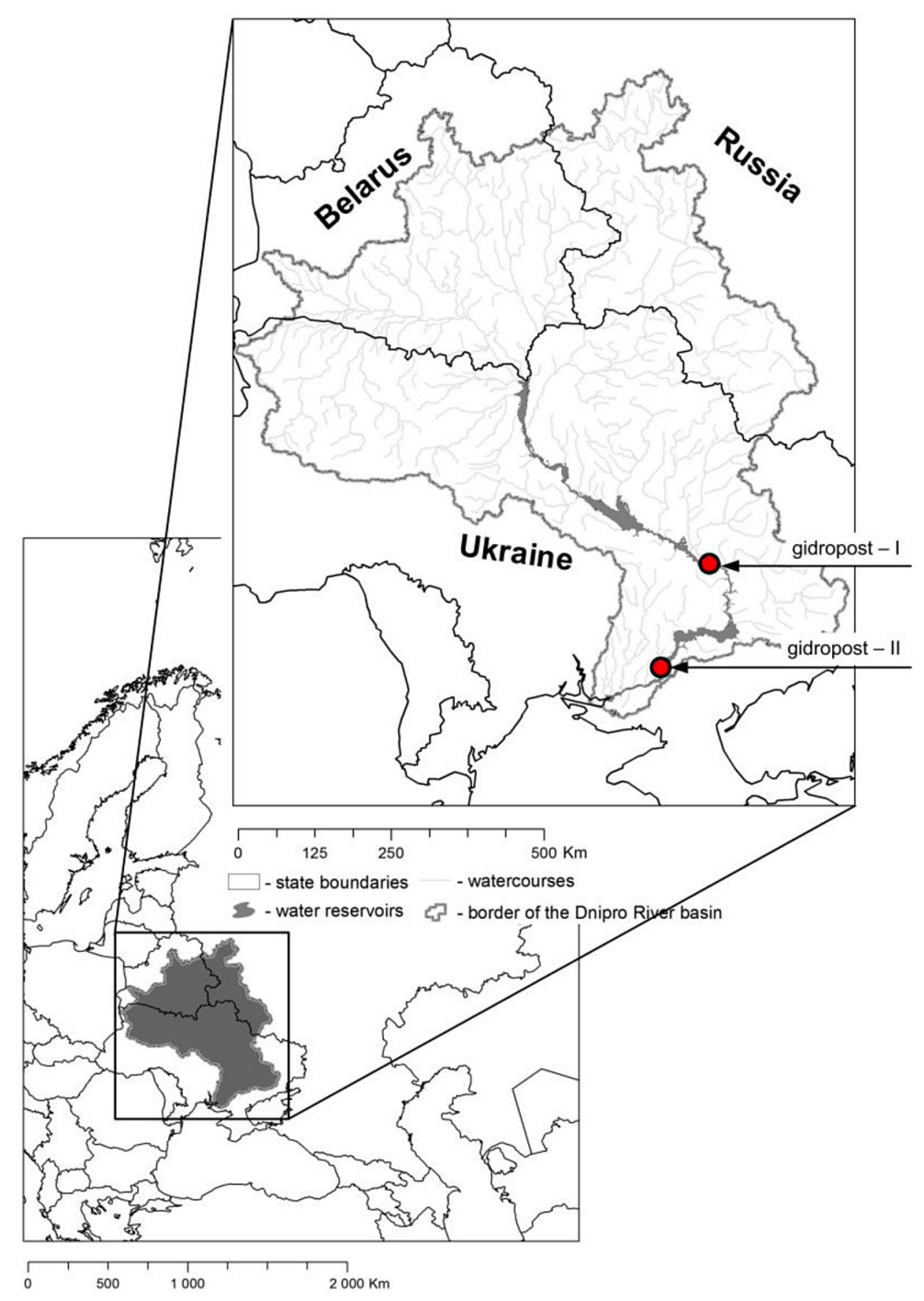

Figure 1. Geographical location of the Dnipro Basin 
$T_{t}$ is the response of the trend component; $S_{t}$ is the response of the seasonal component;

$C_{t}$ is the response of the cyclical component;

$\varepsilon_{t-n}$ is a response of a probabilistic stochastic or unregulated component of the flow change.

The water regime of the Dnieper River is a complex dynamic process that is determined by the superposition of high-frequency (HF) and low-frequency (LF) harmonics of various periodicities with local and global time features that depend on geological, climatic and anthropogenic conditions. Therefore, this complex process was studied using the Wavelet analysis (Mayer, 1995; Yakovlev, 2003) for decomposition of the original series into HF (approximating) and LF (detail) signals, as well as spectral Fourier analysis for determination of the main harmonic (cyclical) components of the river flow dynamics by extraction of sinusoidal components at different frequencies.

Regarding the basic wavelet, the integral wavelet transform of the time series $f(t)$ in the interval $-\infty \leq \mathrm{t} \leq+\infty$ is defined as:

$$
\left(W_{\varphi} f\right)(b, a)=|a|^{-\frac{1}{2}} \int_{-\infty}^{\infty} f(t) \overline{\varphi\left(\frac{t-b}{a}\right)} d t
$$

where $a, b \in R ; \quad a \neq 0$

where: $\varphi(t)$ is the wavelet transform function; $a$ is the time scale, $b$ is the time shift.

With the help of continuous transform, the signal $\varphi(t)$ is transformed from two-dimensional plane into three-dimensional space with coordinates: time $(b)$, scale $(a)$ and amplitude $(c)$. At the same time this signal is decomposed into harmonics with frequencies that correspond to certain scales $(a)$.

The Holt-Winters adaptive time series analysis method (triple exponential smoothing) (Brown, 1971; Kleopatrov et al., 1973; Anderson, 1976) was used to predict changes in the flow of the Dnieper River. It considers the background data of time formation, cyclical and trend component of change in the water regime. This method is one of the most reliable and widely used for prediction purposes.

The licensed software STATISTICA Advanced + QC for Windows v.10 Ru and MathWorks MATLAB 7.9 R2009b was used to analyze, simulate and the predict river flow dynamics.

\section{RESULTS AND DISCUSSION}

Analysis of time series of changes in the flow of the Dnieper River during operation of the cascade of reservoirs, taking into account the reduction in irretrievable consumption of water over the last 40 years, indicates a permanent decrease in the average annual volumes of flow $\left(\mathrm{Q}, \mathrm{m}^{3} / \mathrm{s}\right)$ of the Dnieper River (Fig. 2). It caused increase in water salinity at the lower reaches of the river by $27.4 \%$ (from $0.303 \mathrm{~g} / \mathrm{dm}^{3}$ in Kyiv region to $0.386 \mathrm{~g} / \mathrm{dm}^{3}$ in Kherson region) and the degradation of its ecosystem (Zhukynskyi et al., 1989; Pichura et al., 2015, 2017, 2018).

Despite the stable variational processes of the hydrochemical regime, the insignificant negative trend component is found in the range 1.4-12.2\% in all indicators of the chemical composition (salinity and principal ions) of water. The results of the prediction for the hydrochemical regime of the lower reaches of the Dnieper River showed that all indicators of the chemical composition of water would worsen insignificantly but steadily under the existing conditions of formation (Pichura et al., 2015, 2017, 2018, 2019).

The formation of the water regime is divided into three periods (Fig. 3): period I - natural conditions of formation or before the regulation of the flow (1818-1946); period II -anthropogenic transformation of the flow or the development of new flow conditions (creation of Dnieper reservoirs cascade, 1947-1976); period III - anthropogenic and regulating flow or the stabilization of new flow conditions (since 1977 till today).

The multi-year Q norm was $1607 \mathrm{~m}^{3} / \mathrm{s}$ in the entire retrospective period. The variation value $\mathrm{Cv}=0.28$ and it determines the non-stationary behaviour of the change in the flow of the Dnieper River. The value of kurtosis is more than zero $(E=0.35)$ and it indicates a small frequency of anomalies of changes (deviations) thereof. The value of asymmetry $(\mathrm{A}=0.63)$ determines heterogeneity in the maximum values, which may be a feature of climatically anomalous wet years, when the flow of the river rose to $3000 \mathrm{~m}^{3} / \mathrm{s}$. In the majority of years $(78 \%)$, the average annual value of the flow was in the range from 1000 to $2000 \mathrm{~m}^{3} / \mathrm{s}$ (see Fig. 1a). In $90 \%$ of cases, the flow of the Dnieper River was less than $2200 \mathrm{~m}^{3} / \mathrm{s}$ (see Fig. 2b).

Anomalies of changes in hydrological conditions were determined by the value of the rootmean-square deviation: $Q \geq \pm \sigma$ - strong anomalies and $Q \geq \pm 2 \sigma$ - very strong anomalies, where 

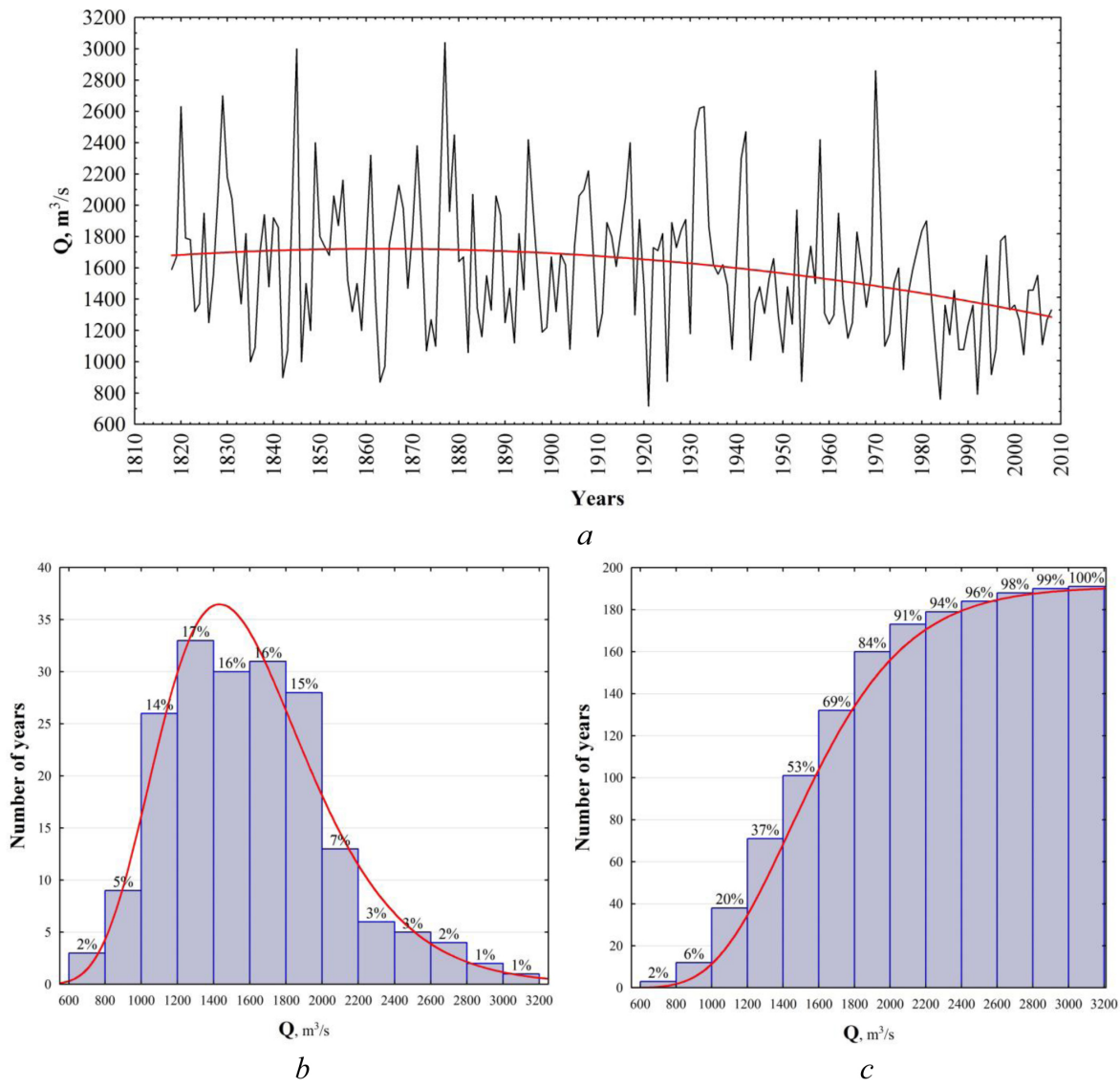

Figure 2. Average annual changes in the flow $\left(\mathrm{Q}, \mathrm{m}^{3} / \mathrm{s}\right)$ of the Dnieper River from1818 till 2008: $a-$ flow dynamics; $b$ - the distribution curve; $c$ - the accumulative frequency of probability of flow change

$\sigma=451.8 \mathrm{~m}^{3} / \mathrm{s}$. Under normal distribution of random values, the following relation is valid:

$$
\left\{\begin{array}{l}
p(-\sigma<T<+\sigma)=0,696, \\
p(-2 \sigma<T<+2 \sigma)=0,963,
\end{array}\right.
$$

where: $p$ is the probability of an event, in this case the probability of non-exceedance of the limit values of anomalies of the average annual flow of the river $(Q)$
Therefore, in about $70 \%$ of cases the absolute value of anomalies of average annual flow is not more than the magnitude. It means that for a period of 190 years, there were 58 years $(30 \%)$ of strong anomalies and 7 years (4\%) of very strong anomalies of hydrological conditions that used to be indicators of the impact of abnormal climate changes before the river regulation. They became a negative consequence of the anthropogenic

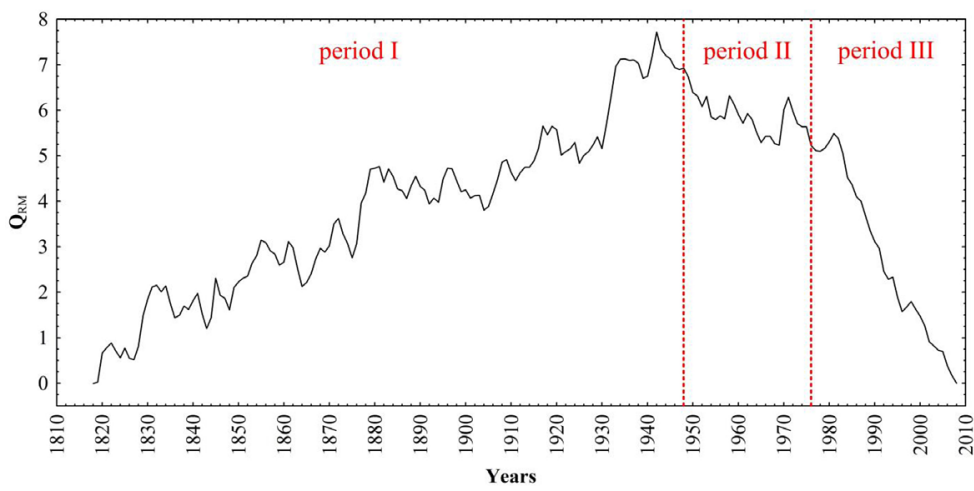

Figure 3. The integral curve of modular ratio $\left(\mathrm{Q}_{\mathrm{MR}}\right)$ of changes in the flow dynamics of the Dnieper River 
transformation of the flow and its artificial regulation after the cascade of Dnieper reservoirs had been built. Strong and very strong anomalies of the average annual flow were determined: in period I - 40 and 6 years, $40 \%$ thereof are abnormally low-flow; period II -9 and 1 years, $56 \%$ thereof are abnormally low-flow; period III -9 years, $100 \%$ thereof are low-flow. The average annual flow over the three periods of its formation decreased 1.26 times (from $1.692 \pm 458 \mathrm{~m}^{3} / \mathrm{s}$ to $1.345 \pm 293 \mathrm{~m}^{3} / \mathrm{s}$ ). The average annual variation of the flow did not change significantly and ranged from 0.22 to 0.29 . Significant changes occurred in the redistribution of the flow: the steady variation dynamics of the water regime $(\mathrm{E}=0.12$, $\mathrm{A}=0.42$ ) in period I changed to the destabilizing processes of its formation in period II $(\mathrm{E}=2.27$, $\mathrm{A}=1.33$ ) with a defined negative trend and cyclical focus and relatively heterogeneous, anthropogenically induced amplitudes of cyclical changes in the average annual value of the flow $(E=-0.42$, $\mathrm{A}=0.02)$ in period III.

We used Meyer wavelet for a detailed study of the signal of dynamic process of water regime of the Dnieper River at various decomposition levels and for determination of the fundamental low-frequency (LF) and high-frequency (HF) harmonics. As a result of decomposition of the initial data $(\mathrm{Q})$ using the global threshold compression method, the energy of the LF signal (A, a) is saved (restored) by $\sim 97.8 \%$ and the wavelet coefficients were zeroed insignificantly - only about $2.2 \%$. This confirms the efficiency of the choice of the wavelet transform function.

Harmonics in the chronological data of the flow dynamics with different localization levels are approximated using multiple-scale wavelet analysis. The chronological series was decomposed to the trend extraction level: $\mathrm{Q}_{\mathrm{T}}=-0,0207 t^{2}+1,9075 t+1677,8$. This provided an opportunity to trace the harmonic motion at different localization levels with stepwise wavelet filtering of the data into approximating (A, a) and detail signals (D, d) (Fig. 4a, b). Wavelet decomposition has the following form $Q(t)=A_{7}(t)+\sum_{i=1}^{7} D_{i}(t)$. The 12-year cyclical components of various amplitudes (Fig. 4d) are clearly observed at the second localization level of the time series. They determine the local periods of high-water and low-water phases.

Harmonics or cyclical components of changes in the water regime at different time scales were studied using wavelet spectrogram $-\mathrm{a}=1 \ldots 60$ (Fig. 4e), where the LF and HF harmonic (cyclical) changes in the flow of the Dnieper River for various localization of the time scale $a$ are determined. The $6 \mathrm{LF}$ harmonics of the water regime formation are visualized in Fig. 4e. They are identified in the spectrogram by lightto-dark transitions through zero values: I - from 1818 till $1840\left(\mathrm{Q}=1733.9 \mathrm{~m}^{3} / \mathrm{s}\right)$, II - from 1841 till $1890\left(\mathrm{Q}=1687.8 \mathrm{~m}^{3} / \mathrm{s}\right)$, III - from 1891 till $1935\left(\mathrm{Q}=1707.1 \mathrm{~m}^{3} / \mathrm{s}\right), \mathrm{IV}-$ from 1936 till 1959 $\left(\mathrm{Q}=1540.6 \mathrm{~m}^{3} / \mathrm{s}\right), \mathrm{V}-$ from 1960 till $1982(\mathrm{Q}$ $\left.=1554.2 \mathrm{~m}^{3} / \mathrm{s}\right), \mathrm{VI}-$ from 1983 till $2008(\mathrm{Q}=$ $1275.0 \mathrm{~m}^{3} / \mathrm{s}$ ). The obtained results of the wavelet analysis enable more accurate determination of three main periods of the change in water regime of the Dnieper River, which had natural conditions and included one low-water and two highwater phases of flow changes from 1818 till 1935 (period I). The new water regime of the Dnieper River started to transform and establish after the first dam of the cascade had been built in 1934 (Zaporizhzhya HES) and after a certain period of its functioning. This period is indicated in the spectrogram from 1936 till 1982 (period II). Since 1983, new conditions of the flow stabilized. We can observe it at the present time. This is period III.

In the period of transformation and establishment of the new water regime of the river, the value of the average annual flow decreased by $157 \mathrm{~m}^{3} / \mathrm{s}$ (from $1704.2 \mathrm{~m}^{3} / \mathrm{s}$ to $1547.2 \mathrm{~m}^{3} / \mathrm{s}$ ) in comparison with the first period. Such a rapid decrease in water content is caused by consumption of large volumes of water for filling of the main reservoirs of the cascade and increase of the consumption of water. In turn, the value of the average annual flow in the third period decreased 1.3 times (up to $1274.7 \mathrm{~m}^{3} / \mathrm{s}$ ), compared to the first period. The maximum values of the average monthly flow reached $13700 \mathrm{~m}^{3} / \mathrm{s}$ (1931) in the first period, $7090 \mathrm{~m}^{3} / \mathrm{s}$ (1970) in the second period, and $4097 \mathrm{~m}^{3} / \mathrm{s}$ (1994) in the third period (Kostianitsyn, 1964). If the multi-year distribution of the flow underwent minor changes during the summer and autumn period, the value of the maximum flow during the spring flooding period in the second and the third period decreased in comparison with the first period 1.9 and 2.6 times, respectively (Fig. 5). The decrease in the flow during the spring and summer period is accompanied by 1.7 times increase in winter flow. During the periods when a certain increase in the 

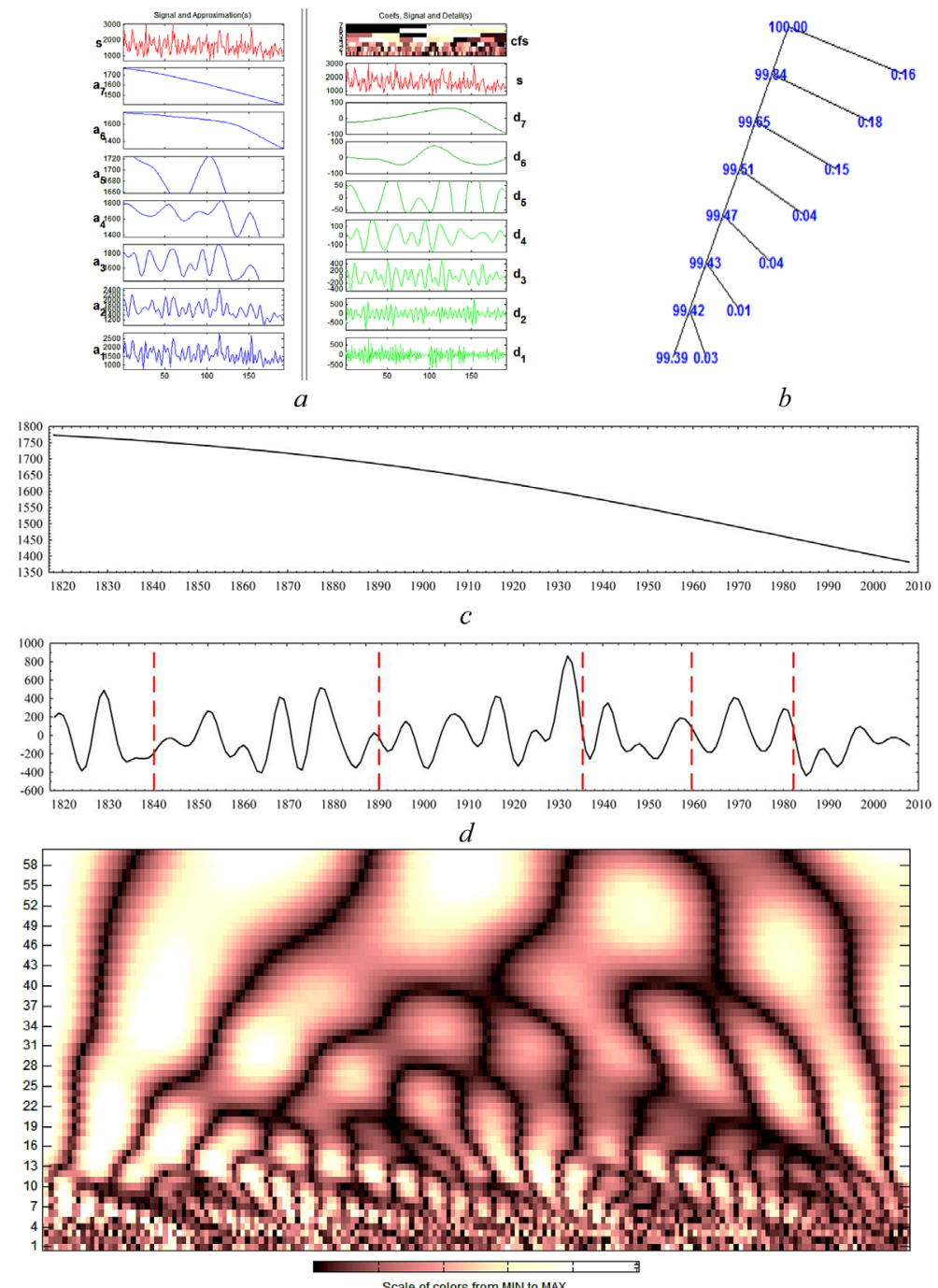

Figure 4. Wavelet decomposition of the flow of the Dnieper River: $a$ - the series decomposition; $b$ - the wavelet-tree of energy conservation (reconstruction) of input signals; $c$ - the trend component; $d$ - the cyclical component for 12-13 years; $e$ - the spectrogram of wavelet coefficients [W $(\mathrm{a}, \mathrm{b})]$ of low-frequency harmonics of changes in the flow

water content of the river might had been expected, it did not occur due to increase in the irretrievable river water consumption.

The construction and operation of the cascade of the Dnieper reservoirs radically changed the water regime of the river. A slight tendency to reduce the flow of the Dnieper River remains today. Current average annual reduction of the flow is $429.5 \mathrm{~m}^{3} / \mathrm{s}$. The maximum value of the flow during this period did not exceed $1780 \mathrm{~m}^{3} / \mathrm{s}$. Annual flow distribution is characterized by weak spring flooding $\left(1680 \mathrm{~m}^{3} / \mathrm{s}\right.$ in average) and low water level in summer and autumn $\left(1090 \mathrm{~m}^{3} / \mathrm{s}\right.$ in average). The average value of the flow in the spring period decreased 1.93 times in comparison with the period before the Dnieper River regulation.

\section{Flow distribution function:}

period I:

$$
\begin{aligned}
& f(Q)=4436 \exp \left[-\left(\left(\frac{t-4,706}{1,21}\right)^{2}\right)\right]+! \\
& +916,1 \exp \left[-\left(\left(\frac{t-5,762}{17,03}\right)^{2}\right)\right], r^{2}=0,997
\end{aligned}
$$

period II:

$$
\begin{gathered}
f(Q)=1656 \exp \left[-\left(\left(\frac{t-4,631}{1,168}\right)^{2}\right)\right]+ \\
+9,689 \cdot 10^{17} \exp \left[-\left(\left(\frac{t+1435}{245,6}\right)^{2}\right)\right], \quad r^{2}=0,904
\end{gathered}
$$


period III:

$$
\begin{gathered}
f(Q)=615,6 \exp \left[-\left(\left(\frac{t-4,991}{0,918}\right)^{2}\right)\right]+ \\
+1643 \exp \left[-\left(\left(\frac{t-3,068}{4,617}\right)^{2}\right)\right]+1561 \exp \left[-\left(\left(\frac{t-12,18}{2,965}\right)^{2}\right)\right], \\
r^{2}=0,994
\end{gathered}
$$

As a result of time modelling of the flow dynamics of the Dnieper River (Fig. 6), the following predictive model was created:

$$
\begin{gathered}
\hat{Y}_{t+n}=\left(\left(\frac{0,8 Y_{t}}{S_{t-12}}+0,2\left(L_{(t-1)}+T_{t-1}\right)\right)+\right. \\
\left.+\mathrm{n}\left(0,2\left(L_{t}-L_{t-1}\right)+0,8 T_{t-1}\right)\right) \cdot\left(0,9 \frac{Y_{t}}{L_{t}}+0,1 S_{t-12}\right)_{t-12+n}
\end{gathered}
$$

where: $L_{t}$ is the influence of the background data of time formation of the flow on the prediction period $t+n$;

$T_{t}$ is the response of the trend component; $S_{t}$ is the response of the seasonal component for the prediction period $t+n ; n=32$ years.

\section{CONCLUSION}

It is determined that if the tendency of anthropogenic and climatic formation of the water regime of the Dnieper River sustains, there is a $90 \%$ probability of insignificant but steady trend and cyclical reduction in the average annual flow by $1.6 \mathrm{~m}^{3} / \mathrm{s}$ per year to $1120 \pm 270 \mathrm{~m}^{3} / \mathrm{s}$ by 2040 . The results of the detailed retrospective analysis over a 190-year period and the prediction of the probability of changes in the flow of the Dnieper River confirm the previous conclusions of many scientists regarding the significant transformation of the ecosystem of the transboundary river and provide new knowledge regarding the main stages of formation of the water regime and the probability of further regulation of the flow of the Dnieper River if the current negative impact of economic activities in the transboundary basin sustains.

\section{REFERENCES}

1. Anderson T. 1976. Statystical analysis of time series. Moscow: Nauka: 343.

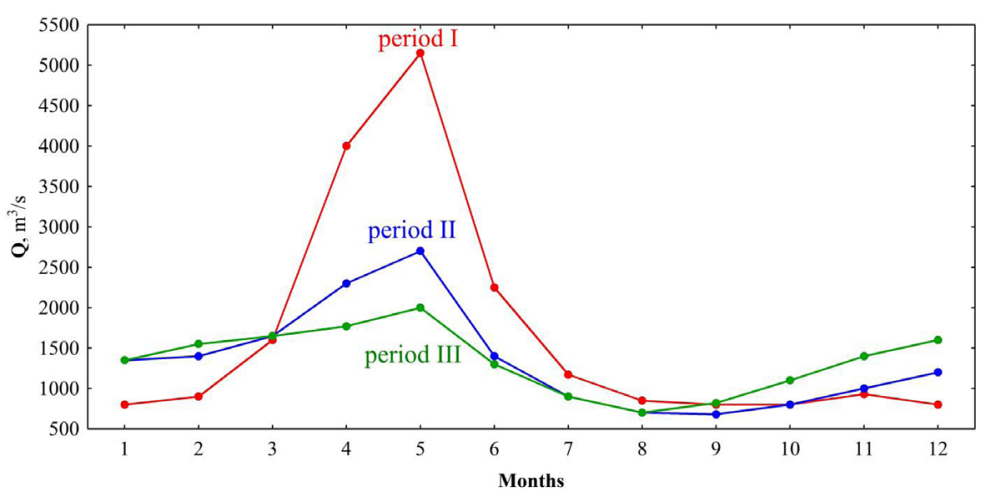

Figure 5. Annual distribution of the flow of the lower Dnieper in different periods of its formation

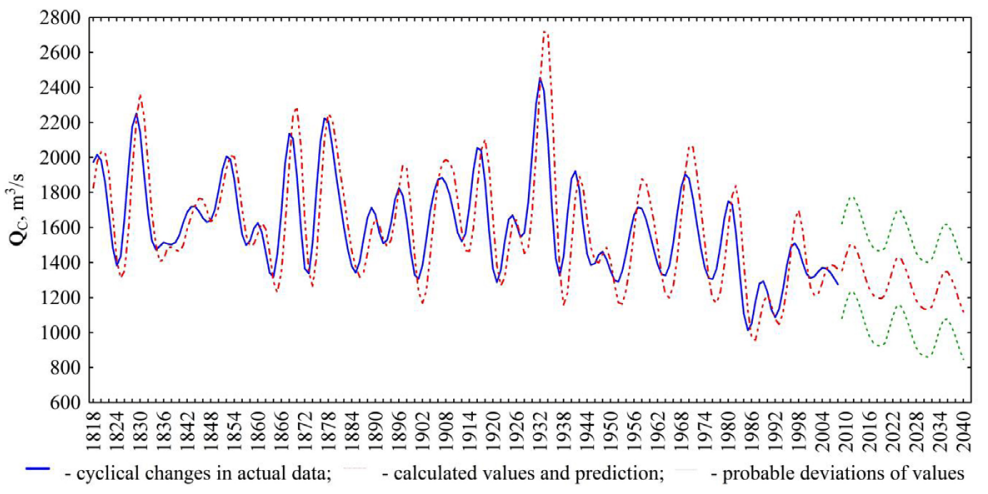

Figure 6. Cyclical components $\left(\mathrm{Q}_{\mathrm{C}}, \mathrm{m}^{3} / \mathrm{s}\right)$ and the prediction of the probability of changes in the flow dynamics of the Dnieper River by 2040 
2. Andrianova O.R., Belevich R.R. and Skipa M.I. 2003. On some distinctive features of the climatic variability of the flow rates of the Danube, Dnieper Rivers and sea level in Odessa in the XX century: http://www.ecologylife.ru/ekologiya-chernogomorya-2003/o-nekotoryih-osobennostyah-klimaticheskoy-izmenchivosti-rashodovrek-dunayadnepra-i-urovnya-morya-v-odesse-v-xx-stoletii. html\#more-1392.

3. Brown R.G. 1971. Economic Order Quantities for Materials Subject to Engineering Changes. Production and Inventory Management 12 (2): P. 89-91.

4. Cesoniene L., Dapkiene M, Sileikiene D., et al 2017. Impact of Plungè City wastewater on water quality of Mažoji Sruoja River. Environmental Research, Engineering and Management 73 (3): 32-43 DOI: http://dx.doi.org/10.5755/j01. erem.73.3.16268

5. Dudiak N.V., Pichura V.I., Potravka L.A. and Stratichuk N.V. 2019. Geomodelling of Destruction of Soils of Ukrainian Steppe Due to Water Erosion. Journal of Ecological Engineering 20 (8): 192-198.

6. Hrebin V.V. 2006. Geographical and hydrological analysis as research method of contemporary changes in water regime of rivers. Hydrology, hydrochemistry and hydroecology 9: 17-30.

7. Jayawardena A.W. Li W.K. and Xu P. 2002. Neighbourhood selection for local modelling and prediction of hydrological time series. Journal of Hydrology 258(1-4): 40-57.

8. Kacienè G. 2018. Pollution of Small Kaunas Rivers with Biogenic Compounds and Heavy Metals. Environmental Research, Engineering and Management 74 (2): 15-22 DOI: http://dx.doi.org/10.5755/j01. erem.74.2.20615

9. Kartvelishvili N.A. 1981. Stochastic hydrology. Leningrad: Gidrometeoizdat: 168.

10. Khilchevskyi V.K. and Romas I.M. 2007. Hydroloho-hydrochemical characteristic of the minimum flow of the rivers of the Dnieper basin. Kyiv: NikaCenter: 184.

11. Kleopatrov D.I. and Frenkel A.A. 1973. Prediction of economic indicators using simple exponential smoothing method. Statistical analysis of economic time series and prediction. Moscow: Nauka: 298.

12. Korzhov Ye.I. 2010. Certain environmentally significant aspects of the water regime of the lower Dnieper. Scientific conference dedicated to the Science day: Collection of research papers. Kherson 3: 4-9.

13. Kostianitsyn M. N. 1964. Hydrology of mouth area of Dnieper and Southern Buh. Moscow: Gidrometeoizdat: 336.

14. Kovalenko V.V., Gaydukova E.V. and Kuassi A.B.G. 2008. Fractal diagnostics of river flow for sustainable description of perennial fluctuations of hydrological characteristics. Meteorology and hydrology 4: 73-80.

15. Kuzmenko Ya. V., Lisetskiy F.N. and Pichura V.I. 2012. Estimation and prediction of the flow of small rivers in the context of anthropogenic impacts and climate change. Modern problems of science and education 6: 1-9

16. Lisetskii F.N., Pichura V.I., Pavlyuk Y.V., et al. 2015. Comparative assessment of methods for forecasting river runoff with different conditions of organization. Research Journal of Pharmaceutical, Biological and Chemical Sciences 6 (4): 56-60.

17. Lisetskii FN, Degtyar AV, Buryak ZhA2015. Rivers and water bodies Belogoriya: Belgorod: Konstanta: $362 \mathrm{p}$.

18. Lisetskiy F.N., Stolba V.F. and Pichura V.I. 2013. Periodicity of climatic, hydrological processes and lake sedimentation in the south of the East European Plain. Contemporary problems of ecology 4: 19-25.

19. Mayer Y. 1995. Wavelets, generalized white noise and fractional: the synthesis of fractional Brownian motion. The Journal of Fourier Analysis and Applications 5 (5): 465-494.

20. Osadchii V. I., Nabyvanets B. I., Osadcha N. M., et al 2008. Hydrochemical reference book. Surface waters of Ukraine. Hydrochemical calculations. Methods of analysis. Kyiv: Nika-Center: 656.

21. Pichura V. I., Malchykova D.S., Ukrainskij P.A., et al 2018. Anthropogenic Transformation of Hydrological Regime of The Dnieper River. Indian Journal of Ecology 45 (3): 445-453.

22. Pichura V.I., Domaratsky Y.A., Yaremko Yu.I. , et al 2017. Strategic Ecological Assessment of the State of the Transboundary Catchment Basin of the Dnieper River Under Extensive Agricultural Load. Indian Journal of Ecology 44 (3): 442-450.

23. Pichura V.I., Pilipenko Yu.V., Lisetskiy F.N., et al 2015. Forecasting of Hydrochemichal Regime of the Lower Dnieper Section using Neurotechnologies. Hydrobiological Journal 51 (3): 100-110.

24. Pichura V.I., Potravka L.A., Dudiak N.V., et al 2019. Retrospective and Forecast of Heterochronal Climatic Fluctuations Within Territory of Dnieper Basin. Indian Journal of Ecology 46 (2): 402-407.

25. Prytkov M. Ya. and Vinogradova O.M. 2007. Zoning of the Lake Ladoga basin under the conditions of the formation of the annual river flow. Geography and natural resources. Science magazine 1: 76-83.

26. Ratkovich D. Ya. and Bolgov M.V. 1997. Stochastic models of fluctuations of the water balance components of river basin. Moscow: 262.

27. Regonda S.K., Sivakumar B. and Jain A. 2004. Temporal scaling in river flow: can it be chaotic? Hydrological Sciences 24: 373-385. 
28. Shvets G.I. 1979. Centuries-long variability of the flow of the Dnieper River. Moscow: Gidrometeoizdat: 84 .

29. Sivakumar B. 2004. Chaos theory in geophysics: past, present and future. Chaos, Solitons and Fractals 19: 441-462.

30. The Ecological Condition of the Dnepr Basin on the territory of Russia 2009: Edited by GM Chernogayeva, AS Zelenov, MS Zelenova, YuA Malevanov, Moscow: Meteoagency Rossgidrometa: 230 p.

31. Vyshnevskyi V.I., Stashuk V.A. and Sakevych A.M.
2011. Hydro-economic complex in the Dnieper basin. Kyiv: Interpress LTD: 188.

32. Yakovlev A. N. 2003. Introduction to wavelet transform. Novosibirsk: Publ. NSTU: 104.

33. Yushkina O.A. 2009. Analysis and prediction of temporal variability of the river flow using nonlinear dynamics methods: thesis abstract ... cand. sc.(geographical). Irkutsk: 20.

34. Zhukynskyi V.N., Zhuravlova L.A. and Ivanov A.I. 1989. Dnieper-Bug estuary system. Kyiv: Naukova dumka: 374. 